\title{
Evaluation of a Psychological Skill Training Program on Mental Toughness and Psychological Wellbeing for Professional Soccer Players
}

\author{
Bülent Okan Miçooğullari ${ }^{1{ }^{* *}, \text { Rıdvan Ekmekçi }}{ }^{2}$ \\ ${ }^{1}$ Department of Physical Education \& Sports, Faculty of Education, Nevşehir Hacı Bektaş Veli University, Turkey \\ ${ }^{2}$ Faculty of Sport Sciences, Pamukkale University, Turkey
}

Copyright $\subset 2017$ by authors, all rights reserved. Authors agree that this article remains permanently open access under the terms of the Creative Commons Attribution License 4.0 International License

\begin{abstract}
The purpose of this study was to evaluate the effectiveness of psychological skills training (PST) in enhancing mental toughness among Turkish professional soccer team. Sixteen weeks of cognitive-behavioral conceptual framework-based PST program designed according to factors (confidence - constancy - control) of Sport Mental Toughness Questionnaire (SMTQ; Sheard et al., 2009) and (self-acceptance, positive relations with others, environmental mastery, purpose in life, personal growth and autonomy) scales of Psychological well-being (SPWB; Dierendonck, 2005). Twenty-six male soccer players between 18-33 years old (mean $\pm s$ : age $26.69 \pm$ 3.54 years) voluntarily participated in this study. The relationship between mental toughness (MT) and psychological well-being was identified by conduction of Pearson Product Moment Correlations. To check effect of PST on MT and PWB in progress Paired sample t test was used. Throughout the intervention program, MT and PWB levels of participants significantly increased, in addition to self-acceptance, autonomy and positive relationships with others. Moreover, positive significant relationships were found between components of PWB and MT.
\end{abstract}

Keywords Psychological Skill Training Program, Mental Toughness, Psychological Well-being, Soccer

\section{Introduction}

Year after year soccer has become a more complicated phenomenon in which optimal performance depends on the cooperation of a number of parameters which include; physiological factors, technical skills, tactical strategies, team factors (e.g., team building and team culture), and psychological skills. Until recently; technical skills, tactical strategies and physiological factors have been given more importance than psychological skills and team factors. As a result, research findings and reports that show and approve the importance of the psychological aspects and team factors for optimal sportive performance have been neglected [1]. This happened in spite of researchers' attempts to highlight the importance of psychological constructs and their positive effects and potential relationship with successful performance $[2,3]$

Psychological skills include a number of different aspects such as motivation, concentration, coping with stress, and anxiety. However, for the purposes of the present study, the following skills will be focused on; a) mental toughness (MT) and b) psychological wellbeing (PWB). These components are considered to be important psychological features that athletes can acquire to be successful in sports environments $[4,5]$. In the process of trials to define MT and PWB, it has been revealed that both of them have common bases and/or features within Positive Psychology [5]. Findings of research studies that investigated PWB and MT concluded that PWB and MT develop knowledge that aspires to support athlete progressing and building [6]. One fundamental link is that both psychological skills and psychological well-being are trainable psychological concepts, essential for health and performance in sport and in general life [7].

Psychological skills are comprised of learned behaviors used by athletes and, if practiced prudently, they have been theorized to serve athletes in their pursuit of sporting excellence [8]. Psychological Skills Training (PST) is a combination of methods designed individually to meet the needs of psychological skills [9]. Psychological skills training (PST) is a process that relates to the development of daily routine activities and capability in relation to settings in sport and exercise [1].

Research findings acknowledge that PST developed mental toughness, promoted psychological development, and helped the successful performance across a variety of 
sports, include swimmers [10], cricketers [11], track \& field athletes [13] and student athletes [5].

Individuals were born with a set amount of mental toughness but also believed that mental toughness was a skill that could be learned and people can be 'toughened-up' with the correct approach to psychological skill training. Connaughton, et al., (2008) and Bull et al., (2005) indicated that mental toughness was a psychological aspect of sports that needed to be developed and maintained to be successful. Development and maintenance of mental toughness was a long-term process and influenced by multiple characteristics and mechanisms [13, 14].

Clough et al. (2002) believe that mental toughness comprises a variety of constructive psychological factors that reduce negative cognitive and somatic effects. This enables athletes to consistently perform well irrespective of situational factors [15]. Moreover, "Mental toughness" is described as the ability to achieve personal goals in the face of pressure from a wide range of different stressors [16] p.70. In other words, mental toughness is not only relevant in the face of adversity but also facilitates an appropriate focus and motivation even when circumstances are favorable [2].

Research findings acknowledge that mental toughness differentiates between more and less successful competitors across a variety of sports, ranging from soccer [4] to equestrian events [17]. Other studies identified specific key psychological skills that affect performance across many sports codes $[2,14,18,19]$. These include self-confidence, self-motivation, attention control, hardiness and enjoyment, ability to handle pressure, resilience, and quality preparation. Similarly, Krane and Williams (2006) concluded that a number of psychological and behavioral skills and strategies (e.g., goal setting, imagery, anxiety control, and coping skills) are associated with peak performance and they further suggested that athletes could master these skills and strategies through psychological skills training and consistent practice. As psychological skills are developed and maintained with training, the benefit from such training accumulates over the years. [20].

Psychological well-being's (PWB) theoretical basement had been divided into two parts; a) the subjective part (hedonic tradition) and b) the objective part (eudaimonic) [21]. The concept of PWB has been defined - in eudaimonic part - as the realizing potential through some form of struggle [7]. PWB is one component of health, which, like psychological skills, falls under the broad category of psychology. PWB has been researched over the last two decades [22]. Studies have demonstrated the positive effect of sports on PWB and PWB on sporting performance $[23,24]$. Psychological explanations of why exercise enhances psychological well-being include the following: enhanced feelings of control, improved self-concept, self-esteem and self-efficacy, and more positive social interactions [25]. Enhanced psychological well-being has been found to coincide with a reduction in negative emotional and physical states, which helps athletes create the optimum training environment to foster performance [26].

PWB orientations are closely examined in Positive Psychology [27] and the knowledge generated from such examinations endeavor to help people thrive and flourish [6]. A high number of studies support the idea that MT be applied into the Positive Psychology (PP), more specifically into situations that relate to sport. One of the reasons for this is because MT seems to duplicate human flourishing and thriving effects among athletes. Likewise, it has been noted that there is a close association between MT and concepts that are closely related to PWB; positive affect [28] and dispositional flow [29], for example.

In line with ideas discussed above, the answers to the following research questions have been sought in the present study:

1. Does psychological skill training contribute to an increase in mental toughness and psychological well-being?

2. Is there a relationship between mental toughness and psychological well-being?

\section{Methodology}

\subsection{Participants}

The sample in this research included soccer players who, at the time of data collection, trained and competed in a Third Division Professional League of the Turkish Football Federation. The sample consisted of 26 soccer players (mean $\pm s$ : age $26.69 \pm 3.54$ years). Participants' age ranged from 18 to 33 years.

\subsection{Measurements}

The Sport Mental Toughness Questionnaire (SMTQ) [30] is a 14-item questionnaire designed to determine athletes' mental toughness levels. Participants respond using a 4-point Likert scale ranging from $1=$ not at all true to $4=$ very true and has an approximately completion time of around $4 \mathrm{~min}$. Total scores for SMTQ and for three subscales can be calculated. A higher mean score indicates a higher degree of mental toughness. Cronbach's alpha for mental toughness-global in the present research was .75. SMTQ has three sub-dimensions: six items for confidence $(\alpha=0.80)$, four items for constancy $(\alpha=0.74)$, four items for control $(\alpha=0.71)$.

In this study, psychological well-being (PWB) has been determined by Ryff's (1989) Scales of Psychological Well-Being (SPW) on the six dimensions of psychological well-being: 1) purpose in life, 2) positive relations with others, 3) autonomy, 4) personal growth, 5) environmental mastery, and 6) self-acceptance. The Ryff's (1989) original 
version consists of six dimensions of 20 items each. Each item is responded using a 6-point Likert scale (1-strongly disagree, 2- moderately disagree, 3- slightly disagree, 4slightly agree, 5- moderately agree, 6- strongly agree) and the scale includes 39 reverse items. However, in order not to bore participants and waste a lot of time, the short version of the survey proposed by van Dierendonck (2005) has been used. In total, there were 39 items for six dimensions. The subscales' length varied from being six-item (self-acceptance, positive relations with others, environmental mastery, and purpose in life) to seven-item (personal growth and eight items for autonomy).

SPWB was translated and adapted to Turkish by Cenkseven (2004) [32]. Reliability studies indicated that Turkish version of the scale is reliable since the Cronbach's Alpha coefficients for each scale was found to range between .74 (personal growth) and .83 (positive relationships with others) while the alpha level for total psychological well-being was .93 . Moreover, test-retest reliability coefficients for each subscale were found to be between .74 (personal growth and positive relationships with others) and .77 (autonomy and environmental mastery). Additionally, reliability for total psychological well-being was .84 .

\subsection{Procedure}

A proposal with information about this research was provided to the officials, coaches and athletes of the Soccer Club at a Division III prior to the start of their pre-midseason program (first week of January). At the first team practice, the researcher discussed the aim and the principles of the research - discussion around the concept of mental toughness and positive psychological well-being-, answered any questions, and obtained written informed consent from the players volunteering to participate in the research. Prior to this, the first measurements were conducted.

The PST program followed in this research has involved four different mental abilities: goal setting, imagery, self-talk and arousal regulation. The four psychological skills were selected in the current program because of the positive and effective relationship between skills and MT PWB. Overall, 16 weeks psychological skills program took place during the season. Each skill's processes lasted for four weeks. PST program phases were ranging in duration from 35-45 minutes per session. Weinberg \& Gould's (2007) PST program phases (education, acquisition and practice) were pursued to practice psychological skills. 16 weeks PST program consisted of 48 sessions totally. For each psychological skill, 12 sessions were conducted. First, four sessions of each skill were for education phase. Four sessions were for acquisition phase of PST and four sessions of program was for practice phase to make corrections and reviews if needed.

\section{Psychological Skill Training Content}

After finishing pre-intervention processes, following techniques were introduced.

Table 1. Psychological skill training content

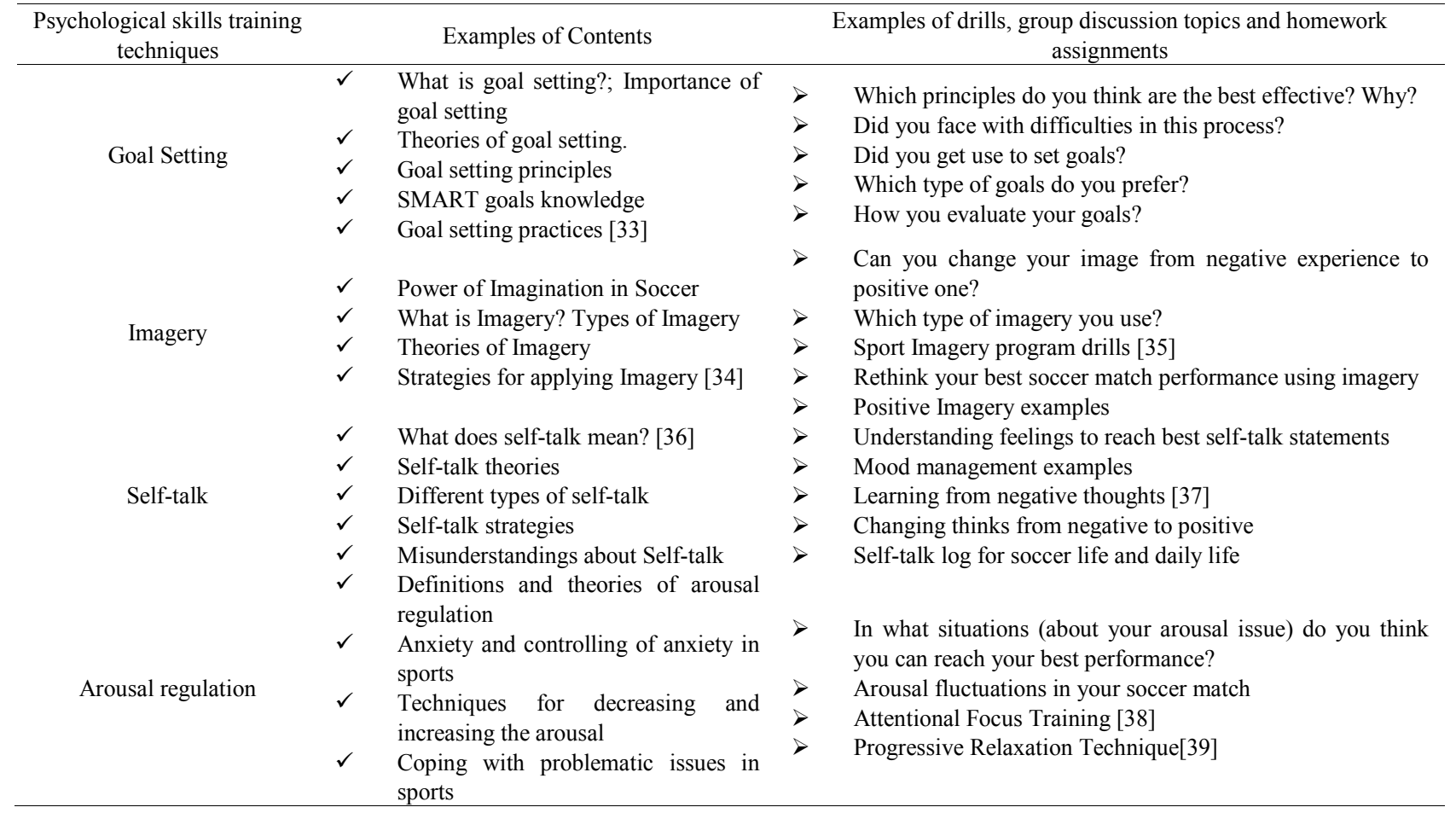




\subsection{Statistical Analysis}

Analysis was conducted using SPSS 21.0. The data was screened for normality and outliers and descriptive statistics for all of the outcome measures were expressed as mean \pm standard deviation. Significant correlations were interpreted with Pearson's moment-correlation [40] and a paired sample t-test with repeated measures was administered.

\section{Results}

Participants were between the ages of 18 and 33, with a mean age of $26.9 \pm 3.7$ years. In this team, $80 \%$ of the participants had played professional soccer for more than ten years.

Kolmogorov-Smirnov and the Shapiro-Wilk tests were used to check the assumptions of normality required for the use of statistical tests later in the analysis. Shapiro-Wilk Test is more appropriate for small sample sizes $(<50$ samples) but can also handle sample sizes as large as 2000 . For this reason, the Shapiro-Wilk test was used for the numerical means of assessing normality. Table 2 shows the results of the Kolmogorov-Smirnov and the ShapiroWilk tests. For both tests, the p-value is greater than .05 so it would accept the null hypothesis that the data comes from a normally-distributed population (Table. 2).

Table 2. Normality test results of parameters

\begin{tabular}{ccccccc}
\hline & \multicolumn{3}{c}{ Kolmogorov-Smirnov } & \multicolumn{3}{c}{ Shapiro-Wilk } \\
& Statistic & df & Sig. & Statistic & df & Sig. \\
\hline SA & .139 & 26 & $.200^{*}$ & .954 & 26 & .385 \\
PR & .085 & 26 & $.200^{*}$ & .977 & 26 & .871 \\
AU & .158 & 26 & .163 & .974 & 26 & .793 \\
EM & .148 & 26 & $.200^{*}$ & .908 & 26 & .062 \\
PL & .125 & 26 & $.200^{*}$ & .960 & 26 & .498 \\
PG & .133 & 26 & $.200^{*}$ & .973 & 26 & .781 \\
PWB & .156 & 26 & .173 & .954 & 26 & .385 \\
CNF & .173 & 26 & .118 & .926 & 26 & .130 \\
CNS & .153 & 26 & .102 & 806 & 26 & .145 \\
CNTL & .161 & 26 & .189 & .924 & 26 & .121 \\
MT & .097 & 26 & $.200^{*}$ & .963 & 26 & .607 \\
\hline
\end{tabular}

Note: $\mathrm{SA}=$ Self-acceptance; $\mathrm{PR}=$ Positive relation with others; $\mathrm{AU}=$ Autonomy; $\mathrm{EM}=$ Environmental mastery; $\mathrm{PL}=$ Purpose of life; $\mathrm{PG}=$ Personal growth; $\mathrm{PWB}=$ Psychological well-being; $\mathrm{CNF}=$ Confidence; $\mathrm{CNS}=$ Constancy; $\mathrm{CNTL}=$ Control and $\mathrm{MT}=$ Mental toughness
Table 3. Descriptive statistics of MT and PWB with sub-dimensions

\begin{tabular}{ccc}
\hline Parameters & Pre Intervention & Post Intervention \\
& Mean (SD) & Mean (SD) \\
\hline SA & $14.60(3.37)$ & $20.72(3.21)$ \\
PR & $-9.18(4.01)$ & $-3.77(4.77)$ \\
AU & $-6.27(2.62)$ & $.27(4.72)$ \\
EM & $10.59(2.48)$ & $11.27(3.64)$ \\
PL & $19.18(3.14)$ & $20.68(3.41)$ \\
PG & $7.55(1.84)$ & $8.54(3.92)$ \\
PWB & $34.56(8.13)$ & $49.41(17.10)$ \\
CNF & $1.75(.32)$ & $2.32(.32)$ \\
CNS & $2.76(.48)$ & $3.25(.57)$ \\
CNTL & $3.18(.79)$ & $3.82(.41)$ \\
MT & $2.45(.33)$ & $3.02(.25)$ \\
\hline
\end{tabular}

Note: $\mathrm{SA}=$ Self-acceptance; $\mathrm{PR}=$ Positive relation with others; $\mathrm{AU}=$ Autonomy; $\mathrm{EM}=$ Environmental mastery; $\mathrm{PL}=$ Purpose of life; $\mathrm{PG}=$ Personal growth; $\mathrm{PWB}=$ Psychological well-being; $\mathrm{CNF}=$ Confidence; $\mathrm{CNS}=$ Constancy; $\mathrm{CNTL}=$ Control and $\mathrm{MT}=$ Mental toughness

Statistically significant differences were found between pre-test and post-test values which were been confidence, constancy, control, mental toughness, self-acceptance, positive relations with others, autonomy, and psychological well-being. The differences observed between the pre-test and post-test of confidence sub-dimension of MT $\mathrm{t}\left({ }_{07}\right)=-9,07, \mathrm{p}=0,000$; constancy sub-dimension of MT $\mathrm{t}\left({ }_{94}\right)=-5,94, \mathrm{p}=0,000$; control sub-dimension of MT $\mathrm{t}\left({ }_{82}\right)=-5,82, \mathrm{p}=.000$; total mean score of MT $\mathrm{t}\left({ }_{92}\right)=-11.92, \mathrm{p}=.000$, were found to be statistically significant $(\mathrm{p} \leq 0.05)$. Moreover, at the other side of the study as PWB; self-acceptance sub-dimension of PWB $\mathrm{t}\left({ }_{00}\right)=6.00, \mathrm{p}=.000$; positive relations with others $\mathrm{t}\left({ }_{55}\right)=-3.55, \mathrm{p}=.002$; autonomy sub-dimension of $\mathrm{PWB}$ $\mathrm{t}\left({ }_{82}\right)=-5.82, \mathrm{p}=.000$; total score of PWB $\mathrm{t}\left({ }_{22}\right)=-3.22$, $\mathrm{p}=.000$ were found to be statistically significant $(\mathrm{p} \leq 0.05)$. It shows that values of confidence, constancy, control, mental toughness, self-acceptance, positive relations with others, autonomy, and psychological well-being increase from pre-test to post-test (Table. 4).

No statistically significant difference was found between the pre-test and post-test of environmental mastery, purpose of life and personal growth sub-dimensions of PWB ( $\mathrm{p} \geq 0.05$ ) (Table. 4). 
Table 4. Findings of paired sample $t$ test

\begin{tabular}{|c|c|c|c|c|c|c|c|c|}
\hline \multicolumn{9}{|c|}{ Paired Differences } \\
\hline & \multirow{2}{*}{ Mean } & \multirow{2}{*}{ SD } & \multirow{2}{*}{$\begin{array}{l}\text { Std. } \\
\text { Error }\end{array}$} & \multicolumn{2}{|c|}{$95 \%$ Conf. Int. of the Dif. } & \multirow{2}{*}{$\mathrm{t}$} & \multirow{2}{*}{ df } & \multirow{2}{*}{ Sig. } \\
\hline & & & & Lower & Upper & & & \\
\hline $\begin{array}{l}\text { Pre-Confidence } \\
\text { Post-Confidence }\end{array}$ &,- 58 & ,28 &, 06 &,- 71 &,- 44 & $-9,07$ & 25 &, 000 \\
\hline $\begin{array}{l}\text { Pre-Constancy } \\
\text { Post-Constancy }\end{array}$ &,- 48 &, 37 & ,08 &,- 66 &,- 32 & $-5,94$ & 25 &, 000 \\
\hline $\begin{array}{l}\text { Pre-Control } \\
\text { Post-Control }\end{array}$ &,- 64 & ,49 &, 11 &,- 87 &,- 41 & $-5,82$ & 25 &, 000 \\
\hline $\begin{array}{l}\text { Pre-MT } \\
\text { Post-MT }\end{array}$ &,- 57 &, 21 &, 05 &,- 67 &,- 47 & $-11,92$ & 25 &, 000 \\
\hline $\begin{array}{l}\text { Pre-Self-acceptance } \\
\text { Post-Self-acceptance }\end{array}$ & 6.14 & 4.79 & 1.02 & 4.01 & 8.26 & 6.00 & 25 & .000 \\
\hline $\begin{array}{l}\text { Pre-Positive relation } \\
\text { Post-Positive relation }\end{array}$ & -5.41 & 7.14 & 1.52 & -8.58 & -2.24 & -3.55 & 25 & .002 \\
\hline $\begin{array}{l}\text { Pre-Autonomy } \\
\text { Post-Autonomy }\end{array}$ & -6.55 & 5.27 & 1.12 & -8.88 & -4.21 & -5.82 & 25 & .000 \\
\hline $\begin{array}{l}\text { Pre-Environmental Mastery } \\
\text { Post-Environmental Mastery }\end{array}$ & -.68 & 4.80 & 1.02 & -2.81 & 1.44 & -.67 & 25 & .513 \\
\hline $\begin{array}{l}\text { Pre-Purpose in life } \\
\text { Post-Purpose in life }\end{array}$ & 1.50 & 5.03 & 1.07 & -.73 & 3.73 & 1.40 & 25 & .177 \\
\hline $\begin{array}{l}\text { Pre-Personal growth } \\
\text { Post-Personal growth }\end{array}$ & -1.00 & 4.71 & 1.00 & -3.09 & 1.09 & -.99 & 25 & .331 \\
\hline $\begin{array}{l}\text { Pre-PWB } \\
\text { Post-PWB }\end{array}$ & -14.86 & 21.63 & 4.61 & -24.45 & -5.28 & -3.22 & 25 & .004 \\
\hline
\end{tabular}

Table 5. Scores of Correlations

\begin{tabular}{|c|c|c|c|c|c|c|c|c|c|c|c|}
\hline & EM & PL & SA & $\mathrm{AU}$ & PG & PR & PWB & $\mathrm{CNF}$ & CNS & CNTL & MT \\
\hline EM & 1 & & & & & & & & & & \\
\hline PL & .399 & 1 & & & & & & & & & \\
\hline SA & $.680^{* *}$ & .111 & 1 & & & & & & & & \\
\hline $\mathrm{AU}$ & $.632^{* *}$ & .266 & $.658^{* *}$ & 1 & & & & & & & \\
\hline PG & $.602^{* *}$ & $.652^{* *}$ & $.478^{*}$ & .333 & 1 & & & & & & \\
\hline PR & .405 & $.763^{* *}$ & .219 & .420 & $.677^{* *}$ & 1 & & & & & \\
\hline PWB & $.806^{* *}$ & $.684^{* *}$ & $.682^{* *}$ & $.724^{* *}$ & $.827^{* *}$ & $.777^{* *}$ & 1 & & & & \\
\hline $\mathrm{CNF}$ & -.002 & .226 & -.185 & .166 & -.203 & .139 & .078 & 1 & & & \\
\hline CNS & .000 & -.290 & .007 & .356 & -.386 & -.172 & -.137 & .130 & 1 & & \\
\hline CNTL & .255 & .006 & .305 & -.011 & .281 & .033 & .169 & -.344 & .226 & 1 & \\
\hline MT & .120 & -.075 & $.540^{*}$ & .318 & -.229 & -.028 & $.482 *$ & .438 & $.842^{* *}$ & $.448^{*}$ & 1 \\
\hline
\end{tabular}

Note: $\mathrm{SA}=$ Self-acceptance; $\mathrm{PR}=$ Positive relation with others; $\mathrm{AU}=$ Autonomy; $\mathrm{EM}=$ Environmental mastery; $\mathrm{PL}=\mathrm{Purpose}$ of life; $\mathrm{PG}=\mathrm{Personal}$ growth; $\mathrm{PWB}=$ Psychological well-being; $\mathrm{CNF}=$ Confidence; $\mathrm{CNS}=$ Constancy; $\mathrm{CNTL}=$ Control and MT= Mental toughness; * $p<0.005 ; * * p<0.001$

Scores of sub-dimensions related with psychological well-being were significantly correlated; self-acceptance and environmental mastery demonstrated the strongest positive relationship $(\mathrm{r} .68, p<.001)$ also positive relations with others and personal growth had similar high correlation score $(\mathrm{r} .67, p<.001)$. Concerning MT and $\mathrm{PWB}$, the strongest positive correlations were observed between the mental toughness and self-acceptance (r.54, $p<.005)$. Both measures, MT and PWB were also significantly related (r.48, $p<.005)$ (Table. 5).

\section{Discussion}

Soccer is one of the most popular sports worldwide and a lot of research has been conducted on various aspects of this sport. In this research, it is aimed to analyze the effects of PST on MT and PWB amongst professional soccer players within the competitive season. The variables of the research - MT and PWB - have common effects on athletes who interest in different disciplines. Those effects can be declared as both of them have human flourishing, thriving effects and dispositional flow on athletes $[6,28,29$, 41]. 
It has been observed that mental toughness develop in the evolution of an athlete to achieve optimal performance [19]. The learned and developed mental toughness parameters distinguish the elite athletes from normal athletes $[42,43]$. In other words, developing these skills is necessary for obtaining success and capable athletes. Because of this, it is no surprise that scientists have apportioned greater interest to define and explain this effective construct in past decades [19]. Following that, MT studies tried to find out traits or attributes of mentally tough athletes those called as super-elite performers but these findings had been criticized because athletes should not be presumed to be knowledgeable of what embodies MT based on the experiences they recollect or their past sporting achievements [3].

The concept of MT and its relationship with sport psychology literature have been studied in very different forms. Studies objectives and participants ranging from rugby league footballers [44], elite athletes [45], cricketers [14], soccer players [4], gymnasts [46], swimmers [10], to equestrian events [47], university student athletes [48], Australian football [19], ultra-endurance runners [49], soccer referees [50], soccer coaches [51], tennis players [52]. All studies' findings are evidence of those psychological skill trainings can be successfully used to develop mental toughness. These studies can be lengthened but it is obvious that MT is crucial and effective component for sport psychology literature.

The scientific attention on PWB within sport and exercise psychology literature has been started in past decades. Initially, PWB had been defined with some psychological and emotional features, include, anxiety, stress, depression, emotion, mood, self-perception etc. Studies found that exercise interventions were effective to develop PWB $[25,53]$.

It has been declared that the contribution of physical activity on psychological well-being through increased mental toughness has yet to be considered. Later on, studies focused on to evaluate relationship between PST interventions with MT and closely associated parameter PWB. Case study interventions have provided rich data on the value of PST programs those designed to evaluate MT and PWB. Results based on quantitative and qualitative outcome and process measurements of PST indicated general improvement in psychological well-being and mental toughness $[5,7,54,55,56,57,58,59]$.

There was a significant relationship between the total MT scores (SMTQ) and total PWB and self-acceptance scores. This supports the claim that characteristics of MT are closely associated to subjective psychological wellness $[5,60]$.

Findings of the study identify which particular components of SMT predict each of the six PWB scales, allowing more specific future interventions to improve well-being. In their study; Miçooğulları, Ödek \& Beyaz found that constancy - which reflects determination, personal responsibility, and an uncompromising attitude can make sense as managing the multiple and complex appeals of athletes - was the strongest predictor of both environmental mastery and purpose in life [61]. Confidence - an unshakable belief in ability - was the strongest predictor of both positive relations with others and self-acceptance [61]. Control subscale - perceived high control over the outcomes of their performance - was not found as the strongest predict of any PWB subscale, but it was found as a moderate predictor of two PWB subscales, which include, autonomy and purpose of life [61].

\section{Conclusions}

It was apparent that the PST program enabled that team to achieve improvements for each of the dependent variables. The PST program appeared to be specifically associated with the improvement of mental toughness and psychological well-being at professional soccer player level. From a psychological states and health perspective, with regard to competition, professional soccer players need to receive, PST programs.

Bull et al. (2005, p. 226) suggest that it is also interesting to note that very little of the output relates directly to psychological skills training', and advise the combination of PST into the convenient environment rather than focusing on such techniques in isolation.

At a theoretical and conceptual level, the PST interventions introduced the relationship between mental toughness and psychological well-being is dependent on how and in what context the concepts are defined, and supported the notion that multiple causal and correlational relationships may exist between psychological well-being and mental toughness both in them and between their components.

Overall, findings of the research demonstrated promising sixteen weeks effects of psychological skills training, not only to develop the perception of the mental toughness of players but also develop their sense of PWB which can also have extensive advances to overall psychological health.

\section{REFERENCES}

[1] Weinberg R.S. \& Gould, D. (2007). Foundations of sport and exercise psychology. Champaign, IL: Human Kinetics.

[2] Gucciardi, D. F., Gordon, S., \& Dimmock, J. A. (2008). Towards an understanding of mental Toughness in Australian football. Journal of Applied Sport Psychology, 20, 261-281.

[3] Crust, L. (2008). A review and conceptual re-examination of mental toughness: Implications for future researchers. Personality and Individual Differences, 45, 576-583. 
[4] Thelwell, R. C., Weston, N. J. V., \& Greenlees, I. A. (2005). Defining and understanding mental toughness within soccer. Journal of Applied Sport Psychology, 17, 326-332.

[5] Golby, J., \& Wood, P. (2016). The Effects of Psychological Skills Training on Mental Toughness and Psychological Well-Being of Student-Athletes. Psychology, 7, 901-913.

[6] Hefferon, K. (2013). Positive Psychology and the Body: The Somatopsychic Side of Flourishing. Maidenhead: Open University Press.

[7] Edwards, D.J. \& Steyn, B.J.M. (2008). Sport psychological skills training and psychological well-being, South African Journal for Research in Sport, Physical Education and Recreation, 30 (1): 15-28.

[8] Kremer, J., \& Moran, A. (2008). Pure sport: Practical sport psychology. London: Routledge.

[9] Gill, D. (2000). Psychological Dynamics of Sport and Exercise, second edition, Champaign, Illinois: Human Kinetics.

[10] Sheard, M., \& Golby, J. (2006). Effect of a psychological skills training program on swimming performance and positive psychological development. International Journal of Sport and Exercise Psychology, 4, 149-169.

[11] Thelwell, R.C., \& Maynard, I.W. (2003). The effect of a mental skills package on "repeatable good performance" in cricketers. Psychology of Sport and Exercise, 4(4), 377-396.

[12] Patrick, T.D., \& Hrycaiko, D.W. (1998). Effects of a mental training package on an endurance performance. The Sport Psychologist, 12, 283-299.

[13] Connaughton, D., Hanton, S., Jones, G., \& Wadey, R. (2008). Mental toughness research: Key issues in the area. International Journal of Sport Psychology, 39, 192-204.

[14] Bull, S. J., Shambrook, C. J., James, W., \& Brooks, J. E. (2005). Towards an understanding of mental toughness in elite English cricketers. Journal of Applied Sport Psychology, 17, 209-227.

[15] Clough, P. J., Earle, K., \& Sewell, D. (2002). Mental toughness: The concept and its measurement. In I. Cockerill (Ed.), Solutions in sport psychology (pp. 32-43). London, UK: Thomson.

[16] Hardy, L., Bell, J., \& Beattie, S. (2014). A neuropsychological model of mentally tough behavior. Journal of Personality, 82, 69-81.

[17] Meyers, M. C., Bourgeois, A. E., Le Unes, A., \& Murray, N. G. (1998). Mood and psychological skills of elite and sub-elite equestrian athletes. Journal of Sport Behavior, 22, 399-409.

[18] Thomas, P. R., \& Over, R. (1994). Psychological and psychomotor skills associated with performance in golf. The Sport Psychologist, 8, 73-86.

[19] Gucciardi, D. F., Gordon, S., \& Dimmock, J. A. (2009). Evaluation of a mental toughness training program for youth-aged Australian footballers: II. A qualitative analysis. Journal of Applied Sport Psychology, 21, pp. 324-339.

[20] Krane, V., \& Williams, J. M. (2006). Psychological Characteristics of Peak Performance. In J. M. Williams (Ed.),
Applied Sport Psychology: Personal Growth to Peak Performance (pp. 207-227). New York: McGraw-Hill.

[21] Ryff, C.D. (1989). Happiness is everything, or is it. Explorations on the meaning of psychological well-being. Journal of Personality and Social Psychology, 57, 1069 1081.

[22] Conway, C., \& Macleod, A. (2002). Well-being: it's importance in clinical research. Clinical Psychology, 16, 26-29.

[23] Edwards, D.J., Edwards, S.D., \& Basson, C.J. (2004). Psychological well-being and physical self-esteem in sport and exercise. The International Journal of Mental Health Promotion, 6, 25-32.

[24] Edwards, S.D., Ngcobo, H.S.B., Edwards, D.J., \& Palavar, K. (2005). Exploring the relationship between physical activity, psychological well-being and physical self-perception in a group of regular exercisers. South African Journal for Research in Sport, Physical Education and Recreation, 27 (1), 75-90.

[25] Scully, D., Kremer, J., Meade, M.M., Graham, R., \& Dudgeon, K. (1998). Physical exercise and psychological well-being: a critical review. British Journal of Sports Medicine, 32, 111-120.

[26] Hardy, L., Jones, G., \& Gould, D. (1996). Understanding Psychological Preparation for Sport: Theory and Practice of Elite Performers. New York: Wiley.

[27] Lambert, L., Passmore, H., \& Holder, M. D. (2015). Foundational Framework of Positive Psychology: Mapping Well-Being Orientations. Canadian Psychology, 56, 311-321.

[28] Mahoney, J. W., Gucciardi, D. F., Ntoumania, N., \& Mallet C. J. (2014). Mental Toughness in Sport: Motivational Antecedents and Associations with Performance and Psychological Health. Journal of Sport and Exercise Psychology, 36, 281-292.

[29] Crust, L., \& Swann, C. (2011). Comparing two measures of mental toughness. Personality and Individual Differences, $50,217-221$.

[30] Sheard, M., Golby, J., \& van Wersch, A. (2009). Progress towards Construct Validation of the Sports Mental Toughness Questionnaire (SMTQ). European Journal of Psychological Assessment, 25, 186-193.

[31] Dierendonck, D., (2005). The construct validity of Ryff's Scales of Psychological Well-being and its extension with spiritual well-being, Personality and Individual Differences $36,629-643$

[32] Cenkseven, F. (2004). Examining the predictors of subjective and psychological well-being of university students. Unpublished doctoral dissertation, Çukurova University, Adana.

[33] Eys, M.A., Patterson, M.M., Loughead, T.M., \& Carron, A.V. (2006). Team building in sport. In J. Duda, D. Hackfort, \& R. Lidor (Eds.), Handbook of research in applied sport psychology: International perspectives (pp. 219-231). Morgantown, WV: Fitness Information Technology.

[34] Morris T., Spittle M., Watt T. (2005) Imagery in sport. 
Champaign, IL: Human Kinetics.

[35] Martens, R. (1987). Coaches guide to sport psychology. Champaign, IL: Human Kinetics.

[36] Hackfort, D., \& Schwenkmezger, P. (1993). Anxiety. In R. N. Singer, M. Murphy, \& L. K. Tennant (Eds.), Handbook of research on sport psychology (pp. 328-364). New York: Macmillan.

[37] Hassmén, P., Hassmén, N., \& Plate, J. (2003). Idrottspsykologi. Stockholm: Natur och Kultur.

[38] Cox, R. H., (2007), Sport psychology: Concepts and applications, McGraw Hill International edition, Columbia.

[39] Hodges, J. (2003). Sports Mind. Sports mind institute for human performance research. Flaxton, Australia.

[40] Tabachnick, B. G., \& Fidell, L. S. (2001).Using multivariate statistics (4th ed.). New York: Harper \& Row.

[41] Gould D, Dieffenbach K, Moffett A (2002). Psychological characteristics and their development in Olympic champions. Journal of Applied Sport Psychology, 14, 172-204.

[42] Stamp, E., Crust, L., Swann, C., Perry, J., Clough, P., \& Marchant, D. (2015). Relationships between mental toughness and psychological wellbeing in undergraduate students. Personality and Individual Differences, 75, 170 174.

[43] Anshel, M. H. (2008). Sport psychology: From Theory to practice (4th ed.). San Francisco, CA: Benjamin Cummings.

[44] Golby, J., \& Sheard, M. (2004). Mental toughness and hardiness at different levels of rugby league. Personality and Individual Differences, 37, 933-942.

[45] Middleton, S. C., Marsh, H.W., Martin, A. J., Richards, G. E., Savis, J., Perry, C., \& Brown, R. (2004). The psychological performance inventory: Is the mental toughness test enough? International Journal of Sport Psychology, 35, 91-108.

[46] Fournier, J. F., Calmels, C., Durand-Bush, N., \& Salmela, J. H. (2005). Effects of a season-long PST program on gymnastic performance and psychological skills development. International Journal of Sport and Exercise Psychology, 3, 59-77.

[47] Blakeslee, M.L., \& Goff, D.M. (2007). The effects of a mental skills training package on equestrians. The Sport Psychologist, 21, 288-301.

[48] Crust, L., \& Azadi, K. (2010). Mental toughness and athletes' use of psychological strategies. European Journal of Sport Science, 10, 43-51.

[49] Crust, L., Nesti, M., \& Bond, K. (2010). Mental toughness and coping in an ultra-endurance event. Athletic Insight, $12(1)$

[50] Slack, L. A., , Maynard, I. W., Butt, J \& Olusoga, P., (2013) Factors Underpinning Football Officiating Excellence: Perceptions of English Premier League Referees, Journal of Applied Sport Psychology, 25:3, 298-315.

[51] Cook, C., Crust L., Littlewood, M., Nesti, M. \& AllenCollinson, J. (2014) 'What it takes': perceptions of mental toughness and its development in an English Premier League Soccer Academy, Qualitative Research in Sport, Exercise and Health, 6 (3): 329-347

[52] Cowden RG. (2017.) On the mental toughness of self-aware athletes: Evidence from competitive tennis players. South African Journal of Science; 113 (1/2).

[53] Biddle, S.J., Fox, K.R., \& Boutcher, S.H. (2000). Physical activity and psychological well-being. London: Routledge.

[54] Smith, R.B., Schutz, R.W., Smoll, F.L., \& Ptacek, J.T. (1995). Development and validation of a multidimensional measure of sport-specific psychological skills: the athletic coping skills inventory-28. Journal of Sport and Exercise Psychology, 17, 379-398.

[55] Tremayne, P., \& Tremayne, B. (2004). Children and sport psychology. In T. Morris \& J. Summers (Eds.), Sport psychology: Theory, applications and issues (2nd ed., pp. 529-546). Milton, Queensland, Australia, Wiley.

[56] Sugiyama, Y., Lee, M., \& Yamazaki, M. (2005). Relation of psychological and social skills in sport to stress coping strategies in daily life. Proceedings of the 11th World Congress of Sport Psychology. August 15 to August 19, Sydney Australia.

[57] Murphy, S. (2005). Applying sport psychology in business settings. Proceedings of the 11th World Congress of Sport Psychology. August 15 to August 19, Sydney Australia.

[58] Birrer, D., \& Morgan, G. (2010). Psychological skills training as a way to enhance an athlete's performance in high-intensity sports. Scandinavian Journal of Medicine \& Science in Sports, 20, 78-87.

[59] Golby, J., \& Sheard, M. (2006). The relationship between genotype and positive psychological developments in national-level swimmers. European Psychologist, 11, 143148.

[60] Sheard, M. (2012). Mental Toughness: The Mindset Behind Sporting Achievement (2nd ed.). East Sussex: Routledge.

[61] Miçooğulları, B.O., Ödek, U. \& Beyaz, Ö., (2017). Evaluation of sport mental toughness and psychological wellbeing in undergraduate student athletes. Educational Research and Reviews, Vol. 12(8), pp. 483-487. 